\title{
Environmental impact and magnitude of paleosol carbonate carbon isotope excursions marking five early Eocene hyperthermals in the Bighorn Basin, Wyoming
}

\author{
Hemmo A. Abels ${ }^{1,2}$, Vittoria Lauretano ${ }^{1}$, Anna E. van Yperen ${ }^{1,3}$, Tarek Hopman ${ }^{1, a}$, James C. Zachos ${ }^{4}$, \\ Lucas J. Lourens ${ }^{1}$, Philip D. Gingerich ${ }^{5}$, and Gabriel J. Bowen ${ }^{6}$ \\ ${ }^{1}$ Department of Earth Sciences, Utrecht University, Budapestlaan 4, 3584 CD Utrecht, the Netherlands \\ ${ }^{2}$ Department of Geosciences and Engineering, Delft University of Technology, Stevinweg 1, $2628 \mathrm{CN}$ \\ Delft, the Netherlands \\ ${ }^{3}$ University of Olso, Sem Sælands vei 1, Blindern, 0371 Oslo, Norway \\ ${ }^{4}$ Department of Earth and Planetary Sciences, University of California Santa Cruz, 1156 High Street, \\ Santa Cruz, CA 95064, USA \\ ${ }^{5}$ Department of Earth and Environmental Sciences, University of Michigan, Ann Arbor, MI 48109, USA \\ ${ }^{6}$ Department of Geology and Geophysics, University of Utah, Salt Lake City, UT 84112, USA \\ anow at: PanTerra, Weversbaan 1-3, 2352 BZ Leiderdorp, the Netherlands
}

Correspondence to: Hemmo A. Abels (h.a.abels@tudelft.nl)

Received: 16 April 2015 - Published in Clim. Past Discuss.: 18 May 2015

Revised: 10 March 2016 - Accepted: 14 March 2016 - Published: 13 May 2016

\begin{abstract}
Transient greenhouse warming events in the Paleocene and Eocene were associated with the addition of isotopically light carbon to the exogenic atmosphere-ocean carbon system, leading to substantial environmental and biotic change. The magnitude of an accompanying carbon isotope excursion (CIE) can be used to constrain both the sources and amounts of carbon released during an event and also to correlate marine and terrestrial records with high precision. The Paleocene-Eocene Thermal Maximum (PETM) is well documented, but CIE records for the subsequent warming events are still rare, especially from the terrestrial realm.

Here, we provide new paleosol carbonate CIE records for two of the smaller hyperthermal events, I1 and I2, as well as two additional records of Eocene Thermal Maximum 2 (ETM2) and H2 in the Bighorn Basin, Wyoming, USA. Stratigraphic comparison of this expanded, high-resolution terrestrial carbon isotope history to the deep-sea benthic foraminiferal isotope records from Ocean Drilling Program (ODP) sites 1262 and 1263, Walvis Ridge, in the southern Atlantic Ocean corroborates the idea that the Bighorn Basin fluvial sediments record global atmospheric change. The $\sim 34 \mathrm{~m}$ thicknesses of the eccentricity-driven hyperther-
\end{abstract}

mals in these archives corroborate precession forcing of the $\sim 7 \mathrm{~m}$ thick fluvial overbank-avulsion sedimentary cycles. Using bulk-oxide mean-annual-precipitation reconstructions, we find soil moisture contents during the four younger hyperthermals that are similar to or only slightly wetter than the background, in contrast with soil drying observed during the PETM using the same proxy, sediments, and plant fossils.

The magnitude of the CIEs in soil carbonate for the four smaller, post-PETM events scale nearly linearly with the equivalent event magnitudes documented in marine records. In contrast, the magnitude of the PETM terrestrial CIE is at least $5 \%$ smaller than expected based on extrapolation of the scaling relationship established from the smaller events. We evaluate the potential for recently documented, nonlinear effects of $p \mathrm{CO}_{2}$ on plant photosynthetic $\mathrm{C}$-isotope fractionation to explain this scaling discrepancy. We find that the PETM anomaly can be explained only if background $p \mathrm{CO}_{2}$ was at least $50 \%$ lower during most of the post-PETM events than prior to the PETM. Although not inconsistent with other $p \mathrm{CO}_{2}$ proxy data for the time interval, this would require declining $\mathrm{pCO}_{2}$ across an interval of global warming. A more likely explanation of the PETM CIE anomaly in pedogenic 
carbonate is that other environmental or biogeochemical factors influencing the terrestrial CIE magnitudes were not similar in nature or proportional to event size across all of the hyperthermals. We suggest that contrasting regional hydroclimatic change between the PETM and subsequent events, in line with our soil proxy records, may have modulated the expression of the global CIEs in the Bighorn Basin soil carbonate records.

\section{Introduction}

During the late Paleocene and early Eocene around 60 to 50 million years ago, massive amounts of carbon were released in pulses into the ocean-atmosphere exogenic carbon pool causing a series of transient global warming events, known as hyperthermals (Kennett and Stott, 1991; Cramer et al., 2003; Zachos et al., 2005; Lourens et al., 2005). These events represent the best paleoanalogs for current greenhouse gas warming, despite the very different background climatic, atmospheric, and geographic conditions, and potentially the different timescales on which they occurred (Bowen et al., 2006, 2015; Zachos et al., 2008; Cui et al., 2011). The largest of the hyperthermals, the Paleocene-Eocene Thermal Maximum (PETM) at 56 million years ago, is known to have caused severe climatic and marine and terrestrial biotic change (Thomas, 1989; Gingerich, 1989; Kennett and Stott, 1991; Koch et al., 1992), comprehensively reviewed in McInerney and Wing (2011). Recently, records of the secondary hyperthermals (i.e., Eocene Thermal Maximum 2 (ETM2H1) and 3 (ETM3-K)) have become available (Cramer et al., 2003; Lourens et al., 2005; Nicolo et al., 2007; Abels et al., 2012; Chen et al., 2014; Lauretano et al., 2015), while their environmental and biotic impact has yet to be resolved (Sluijs et al., 2009; Stap et al., 2010a, b; Abels et al., 2012; D'Haenens et al., 2014).

All hyperthermals are characterized by a distinct geochemical signature, a negative carbon isotope excursion, indicating that the carbon released to the exogenic carbon pool during these events had a dominant biogenic origin (Dickens et al., 1995). The potential biogenic sources range from plant material to methane. With the carbon isotope excursions and independent constraints on the mass of carbon release, it should be possible to identify the source. The mass can be constrained by several approaches, for example quantifying ocean acidification or $p \mathrm{CO}_{2}$ by proxy, either directly (e.g., by epsilon $p$ ) or indirectly (e.g., by sea surface temperature, SST) (Dickens et al., 1997; Dickens, 2000; Bowen et al., 2004; Ridgwell, 2007; Panchuk et al., 2008; Zeebe et al., 2009), though the uncertainty with these approaches is large (Sexton et al., 2011; DeConto et al., 2012; Dickens, 2011). Nevertheless, in theory, if there was a single source of carbon for all carbon isotope excursion (CIE), the scaling with mass should be predictable. This requires that, firstly, the exact size of the CIEs in the global exogenic carbon pool during hyper- thermal events be well constrained and, secondly, the factors that fractionating $\mathrm{C}$ isotopes between the substrate reservoirs and organic and carbonate proxies be well understood (Sluijs and Dickens, 2012).

Paleosol or pedogenic carbonate is precipitated from $\mathrm{CO}_{2}$ that stems from respiration of roots and plant litter in the soil and from atmospheric $\mathrm{CO}_{2}$ diffusing into the soil. Plant $\mathrm{CO}_{2}$ from $\mathrm{C}_{3}$ plants is typically fractionated by -16 to $-24 \%$ o compared to atmospheric $\mathrm{CO}_{2}$ (O'Leary, 1988). Paleosol carbonate is a mix of both isotopically distinct sources, modified by fractionation associated with diffusion, carbonate equilibrium, and calcite precipitation and therefore registers values between -7 and $-11 \%$ in non-hyperthermal conditions in Paleogene soils covered by $\mathrm{C}_{3}$ vegetation. Paleosol carbonate records the atmospheric carbon isotope excursions related to the PETM, though amplified with respect to marine carbonate (Bowen et al., 2004). This amplification has been attributed to increased soil productivity and humidity during the hyperthermal events (Bowen et al., 2004; Bowen and Bowen, 2008) by changing plant communities (Smith et al., 2007) and by higher $p \mathrm{CO}_{2}$ (Schubert and Jahren, 2013).

In a recent study, the carbon isotope anomalies associated with ETM2 and H2 were documented in paleosol carbonate, allowing for comparison of the terrestrial amplification of the CIEs relative to the PETM (Abels et al., 2012). An apparent linear scaling of the marine and terrestrial carbon isotope excursions for the PETM, ETM2 and H2 events was invoked to suggest that all three events may have reflected a common mechanism of global change. Interpretation of this signal is complicated, however, by shifting background climate conditions between the events, which are separated by close to 2 million years of gradual greenhouse warming (Zachos et al., 2008; Littler et al., 2014), and by the fact that the observed relationship did not converge on the origin, leaving the carbon isotope scaling associated with smaller events (e.g., I1 and I2) uncertain.

Here, we extend the existing record of three hyperthermals from the Bighorn Basin with data documenting two new CIEs (I1 and I2). We further report additional records of the ETM2 and H2 CIEs within the Basin and analyze bulk oxides in thick $(>0.75 \mathrm{~m})$ soils to reconstruct soil moisture values through these greenhouse warming events. We compare our records with the new benthic foraminiferal records generated for Ocean Drilling Program (ODP) Site 1263 at Walvis Ridge, Atlantic Ocean (Lauretano et al., 2015), and a bulk sediment carbon isotope record from ODP Site 1262 (Zachos et al., 2010; Littler et al., 2014), Walvis Ridge, to investigate coeval carbon isotope change and registration of multiple CIEs in the different carbonate proxies. We analyze these records in the context of the recently characterized dependence of plant carbon isotope fractionation on atmospheric $\mathrm{CO}_{2}$ partial pressure (Schubert and Jahren, 2012), including scenarios that allow for changing background conditions across the late-Paleocene-early-Eocene. 


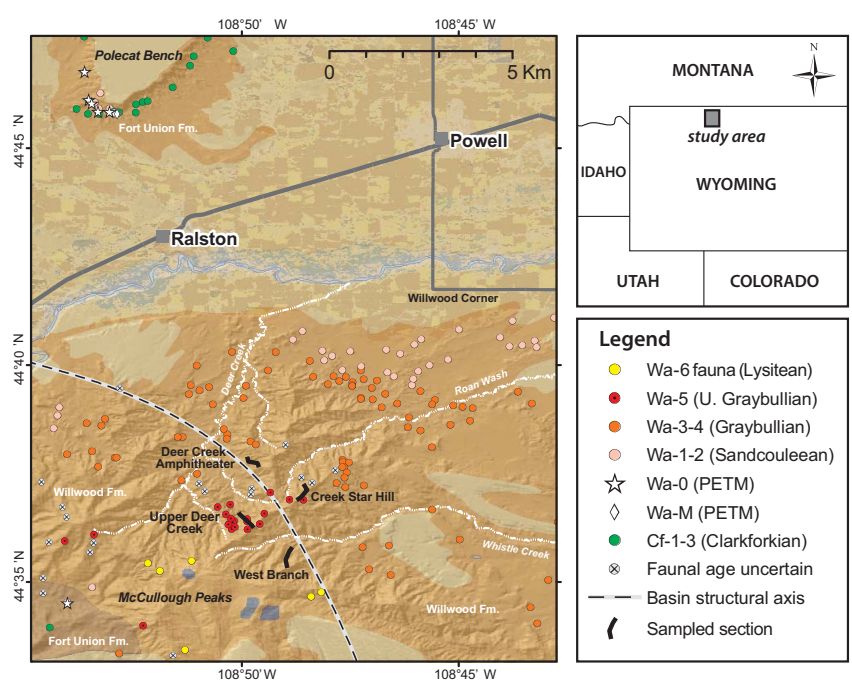

Figure 1. Location map of the sampling sites in the McCullough Peaks area of the northern Bighorn Basin in northeastern Wyoming (USA). Background colors denote topography; grey lines are roads. Indicated are the fossil localities and their interpreted Wasatchian mammal zone and the four study sections. Polecat Bench in the northwest of the study sites is the location of the PETM.

\section{Material and methods}

Pedogenic carbonate nodules were sampled at $12.5 \mathrm{~cm}$ spacing where present after removal of the weathered surface in the West Branch and Creek Star Hill sections located in the McCullough Peaks area of the northern Bighorn Basin, Wyoming (USA; Fig. 1). Sediment samples from soil-B horizons for the reconstruction of mean annual precipitation (MAP) are from the same sections and from the Upper Deer Creek section of Abels et al. (2012).

Micritic parts of the nodules were cleaned and ground to powder, while spar was taken out after crushing the nodule into a few pieces. Carbon isotope ratios of carbonate micrite were measured using a SIRA-24 isotope ratio mass spectrometer of VGs (vacuum generators) at Utrecht University (Netherlands). Prior to analysis, samples were roasted at $400{ }^{\circ} \mathrm{C}$ under vacuum before reaction with dehydrated phosphoric acid in a common-bath system for series of 32 samples and 12 standards. Carbon isotope ratios are reported as $\delta^{13} \mathrm{C}$ values, where $\delta^{13} \mathrm{C}=\left(R_{\text {sample }} / R_{\text {standard }}-1\right)$, reported in per mil units (\%o), and the standard is VPDB. These isotope ratio measurements are normalized based on repeated measurements of in-house powdered carbonate standard (Naxos) and analytical precision was calculated from the inclusion of three IAEA-CO1 standards in every series of 32 samples. Analytical precision is $\pm 0.1 \%$ or for $\delta^{13} \mathrm{C}(1 \sigma)$, whereas variability within individual paleosols averaged $0.2 \%$.

To calculate CIE magnitudes, carbon isotope records are first detrended to exclude the influence of the long-term Paleocene to early Eocene trends. The CIE magnitudes are then calculated as the difference between pre-excursion carbon isotope values and excursion values within the core of the main body (Table 1; Supplement). Standard errors are calculated using variability in background and excursion values.

\section{Results}

\subsection{Bighorn Basin}

High-resolution pedogenic carbonate carbon isotope records are constructed for the lower Eocene of the Willwood Formation in the McCullough Peaks area, northern Bighorn Basin, Wyoming (USA; Fig. 1). Previous work included the Upper Deer Creek (UDC) section, where the carbon isotope excursions of ETM2 and H2 hyperthermal events were located (Abels et al., 2012). Here, we analyze two parallel sections, the Creek Star Hill (CSH) and West Branch (WB) sections, separated by 1 to $2 \mathrm{~km}$ from the UDC section (Fig. 1). The isotope record is extended upwards in the WB section and downwards in the Deer Creek Amphitheater section (DCA; Abels et al., 2013). We construct a composite stratigraphic section by connecting the four sections via lateral tracing of marker beds in the field, such as the P1 to P8 purple soils in the ETM2-H2 stratigraphic interval (Abels et al., 2012).

The carbon isotope record of paleosol carbonate of the McCullough Peaks (MCP) composite section shows four CIEs (Fig. 2). The lower excursions of $\sim 3.8$ and $\sim 2.8 \%$ o in magnitude (see methods for CIE magnitude calculation) have previously been related to the ETM2-H1 and $\mathrm{H} 2$ events (Abels et al., 2012) and are shown to be similar in the parallel Upper Deer Creek, West Branch, and Creek Star Hill sections. This confirms the presence and regional preservation of these CIEs in the Willwood Formation. The two younger carbon isotope excursions are $\sim 2.4$ and $\sim 1.6 \%$ in magnitude and both located in the West Branch section (Fig. 2). These excursions likely relate to the CIEs of the I1 and I2 events that occur in the subsequent $405 \mathrm{kyr}$ eccentricity maximum after ETM2-H1 and H2 (Cramer et al., 2003).

Besides these CIEs, several intervals show less welldefined negative carbon isotope excursions of $\sim 0.5-1 \%$ : two below ETM2 at MCP meter levels 95 and 145, two above $\mathrm{H} 2$ at meter levels $\sim 260$ and $\sim 290$, and one above I2 at meter 400 . This scale of variability is harder to detect as the carbon isotopes show a background variability of $\sim 1 \%$ o $(2 \sigma)$, possibly noise related to local environmental factors. The spacing between the CIEs and the low-amplitude variability in the MCP section is on average $\sim 34 \mathrm{~m}$. Bandpass filtering of this scale of variability specifically shows a strong coherent variation through the ETM2 to I2 interval (Fig. 3).

Precession forcing of overbank-avulsion lithological cyclicity in the Willwood Formation was recently substantiated with data from the Deer Creek Amphitheater section (Abels et al., 2013). In the DCA section, the cyclicity occurs on a scale of $\sim 7.1 \mathrm{~m}$. In the three sections now covering ETM2-H2, the cyclicity has a very similar average thickness 
Table 1. Magnitudes of carbon isotope excursions for five Paleocene-Eocene hyperthermal events in paleosol carbonate of the Bighorn Basin, Wyoming (USA), and benthic foraminiferal and bulk sediment carbonate of Walvis Ridge sites 1263 and 1262 , Atlantic Ocean. Standard errors (SEs) of the differences between detrended background variability and excursion variability are given (see the "Material and methods" section).

\begin{tabular}{|c|c|c|c|c|c|c|c|c|}
\hline Event & $\begin{array}{c}\text { Bighorn Basin } \\
\text { CIE pedogenic carbonate }\end{array}$ & SE & $\begin{array}{l}\text { Bighorn Basin } \\
\text { CIE } n \text { alkanes }\end{array}$ & SE & $\begin{array}{c}\text { Walvis Ridge } \\
\text { sites } 1263 \text { and } 65 \\
\text { CIE benthic foraminifera }\end{array}$ & SE & $\begin{array}{c}\text { Walvis Ridge } \\
\text { Site } 1262 \\
\text { CIE bulk carbonate }\end{array}$ & SE \\
\hline PETM & 5.90 & 0.86 & 4.23 & 0.67 & 3.38 & 0.12 & 1.93 & 0.08 \\
\hline EMT2-H1 & 3.78 & 0.56 & & & 1.30 & 0.18 & 0.89 & 0.05 \\
\hline $\mathrm{H} 2$ & 2.75 & 0.38 & & & 0.97 & 0.16 & 0.58 & 0.06 \\
\hline I1 & 2.42 & 0.45 & & & 0.88 & 0.16 & 0.63 & 0.07 \\
\hline $\mathrm{I} 2$ & 1.55 & 0.72 & & & 0.73 & 0.16 & 0.50 & 0.10 \\
\hline
\end{tabular}

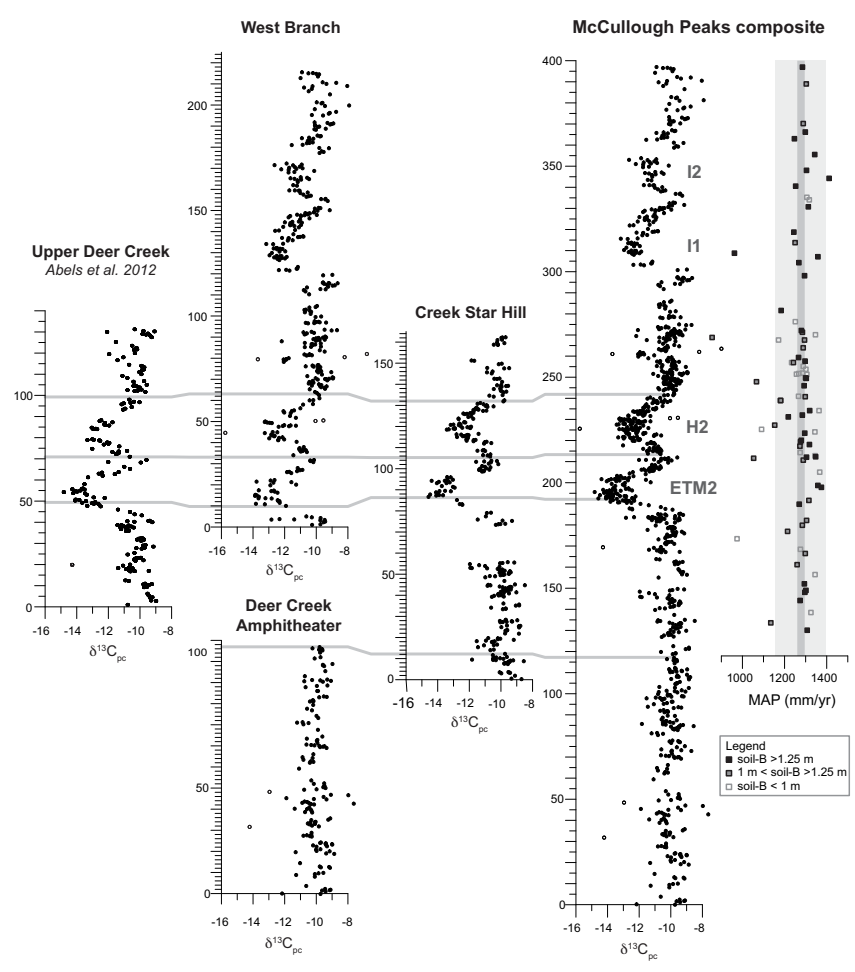

Figure 2. Carbon isotope stratigraphies of paleosol carbonate in the McCullough Peaks area, Bighorn Basin, Wyoming (USA). Shown are data from the Upper Deer Creek section of Abels et al. (2012), and the West Branch, Deer Creek Amphitheater, and Creek Star Hill sections. Grey horizontal lines represent field-based tracing of marker beds P1, P4, and P8 by which the McCullough Peaks composite carbon isotope stratigraphy has been constructed. To the right, mean annual precipitation reconstructions from the CALMAG methods are given on the McCullough Peaks composite stratigraphy. Different symbols denote different thickness of the soil-B horizons. Note that there is no obvious change in soil moisture during the four hyperthermal events.

of $\sim 7.1 \mathrm{~m}$. The precession cyclicity comprises heterolithic sandy intervals showing little pedogenic imprint alternating with mudrock intervals showing intense pedogenesis. In the

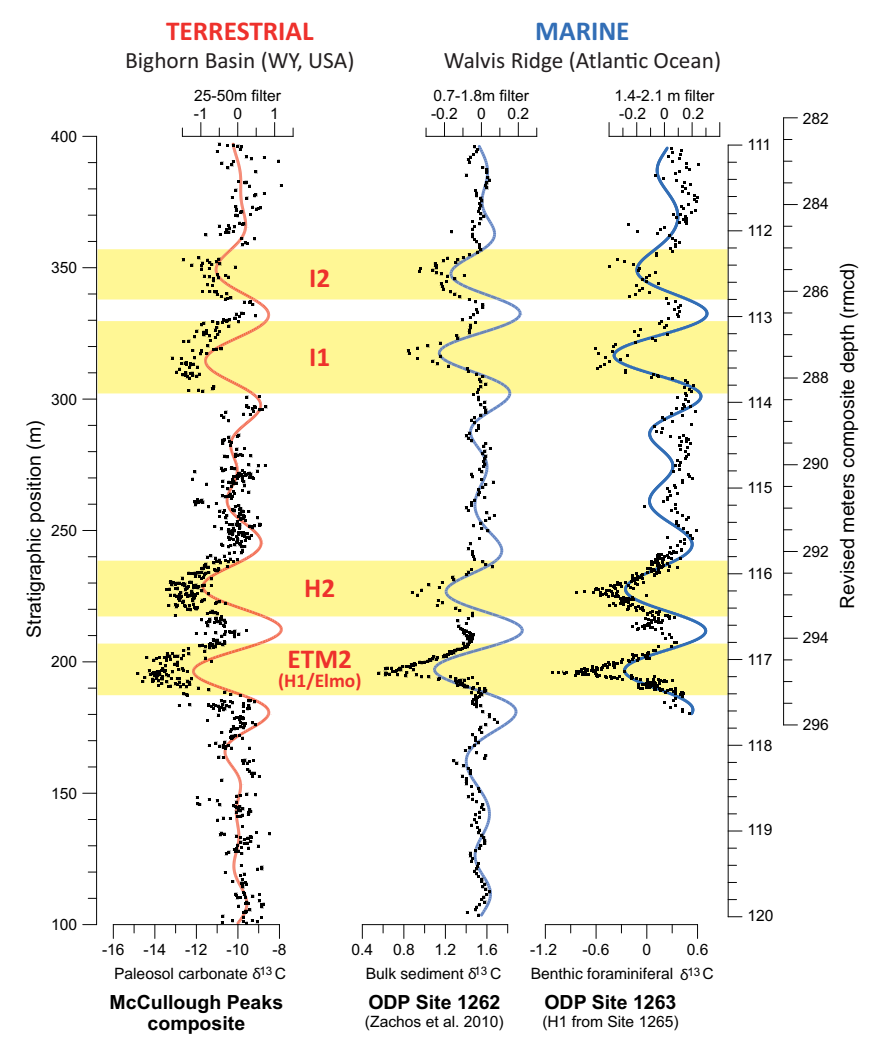

Figure 3. The McCullough Peaks paleosol carbonate carbon isotope stratigraphy compared in-depth domain to the bulk sediment and benthic foraminiferal (Nuttallides truempyi) carbon isotope stratigraphies at, respectively, ODP Site 1262 (left $y$ axis on right side; Zachos et al., 2010) and 1263 (right $y$ axis on right side; Stap et al., 2010a; this study) at Walvis Ridge in the southern Atlantic Ocean. Filters denote the $\sim 100$ kyr eccentricity band in the three records. Note that linear stretching of depth scales is sufficient to construct the figure, indicating the constant average sedimentation rates on longer timescales in both realms. On smaller timescales, large sedimentation rate differences occur that in the marine realm relate to carbonate dissolution during and carbonate overshoot after the hyperthermal events. 
precession forcing sedimentary synthesis, the heterolithic intervals are related to periods of regional avulsions and rapid sedimentation, while the mudrocks are related to periods of overbank sedimentation when the channel belt had a relatively stable position (Abels et al., 2013). This scale of sedimentary cyclicity is also observed higher in the West Branch section. Average climatic precession cycles in the Eocene last $\sim 20 \mathrm{kyr}$ resulting in $\sim 7.1 \mathrm{~m}$ of sediment. This gives an average sedimentation rate of $\sim 0.35 \mathrm{~m} \mathrm{kyr}^{-1}$, resulting in $\sim 96 \mathrm{kyr}$ for the $34 \mathrm{~m}$ cyclicity observed in the carbon isotope records in the ETM2-I2 interval. This is in line with $\sim 100 \mathrm{kyr}$ eccentricity forcing of individual hyperthermals and a 405 kyr eccentricity forcing of the ETM2-H2 and I1-I2 couples.

We produce MAP estimates across the ETM2-I2 interval with the CALMAG method, which uses bulk oxide ratios in soil-B horizons (Nordt and Driese, 2010). Conservatively the method reconstructs soil moisture contents in these ancient soils. Ideally, soil-B horizons thicker than $1 \mathrm{~m}$ should be used for this proxy (Adams et al., 2011). We measured all 59 soil-B horizons thicker than $1 \mathrm{~m}$, where possible in multiple, parallel sections. In addition, we measure 24 soil-B horizons between 0.5 and $1 \mathrm{~m}$. Our estimates from the 83 individual soils show a stable soil moisture regime in the early Eocene Bighorn Basin with mean annual precipitation estimates of around $1278 \mathrm{~mm} \mathrm{yr}^{-1}\left(2 \sigma 132 \mathrm{~mm} \mathrm{yr}^{-1}\right.$; Fig. 2). All except one soil-B horizon thicker than $1.25 \mathrm{~m}$ fall in this range. Soil-B horizons below $1.25 \mathrm{~m}$ thickness occasionally show drier outliers, of which three are below $1000 \mathrm{~mm} \mathrm{yr}^{-1}$. There are no striking changes during the ETM2, H2, I1, or I2 hyperthermal events. The 5 soils that contribute to our ETM2 reconstructions show a potentially slightly enhanced soil moisture content with reproduced annual rainfall of $1337\left(2 \sigma 88 \mathrm{~mm} \mathrm{yr}^{-1}\right)$, while the 11 soils in $\mathrm{H} 2$ show $1267 \mathrm{~mm} \mathrm{yr}^{-1}( \pm 166)$, no different from reconstructions for background climate states. There are slightly more dry outliers both in as well as just outside the hyperthermals, especially $\mathrm{H} 2$, but it should be noted that these intervals also have denser sampling because of the replication of data for these intervals in three parallel sections.

\subsection{Walvis Ridge}

For a comparison of time equivalent carbon isotope change, we use existing and new benthic foraminiferal Nuttallides truempyi records from Site 1263 (McCarren et al., 2008; Stap et al., 2010a; Lauretano et al., 2015), the shallowest site of Walvis Ridge, with a paleodepth of $\sim 1500 \mathrm{~m}$. For Site 1263, because $N$. truempyi specimens are absent in the main body of the PETM, the benthic record includes data for the infaunal species Oridorsalis umbonatus, which is isotopically similar (McCarren et al., 2008). The O. umbonatus data cover most of the CIE though no shells were recovered from the lowermost portion of the clay layer. Data for the ETM2-H2 events are from Stap et al. (2010a), and data for I1-I2 are from Lauretano et al. (2015). Benthic foraminifera are mostly absent within the Elmo clay layer at Site 1263. A compilation of all Walvis Ridge sites shows very similar benthic carbon isotope excursion values for ETM2 (Stap et al., 2010a). Therefore, we use the next-shallowest site, 1265 (paleodepth $\sim 1850 \mathrm{~m}$ ), to cover the missing ETM2 peak excursion values at Site 1263. The data from N. truempyi at Site 1263, generated at $5 \mathrm{~cm}$ resolution across the I1 and I 2 events, show benthic CIEs of $0.88 \%$ for I1 and $0.73 \%$ o for I2 (Fig. 3).

As a framework for correlation, we plot the long, highresolution bulk carbonate carbon isotope record from ODP Site 1262 (Zachos et al., 2010) and the benthic carbon isotope record from ODP Site 1263 (Fig. 3). Site 1262 is the deepest site from the ODP Leg 208 Walvis Ridge transect, with an approximate paleodepth of $3600 \mathrm{~m}$. The Site 1262 carbon isotope record is orbitally tuned (Westerhold et al., 2008) and captures all Eocene CIE, PETM, ETM2, H2, I1 and I2 events (Zachos et al., 2010; see also Littler et al., 2014), though the PETM is clearly truncated due to dissolution (Zachos et al., 2005).

\section{3 $\mathrm{CIE}$ comparison with fixed background $p \mathrm{CO}_{2}$}

The new records show that CIE magnitudes of both terrestrial and marine substrates decrease progressively across the five hyperthermal events (Fig. 4). For the four smaller events, the pedogenic carbonate and benthic foraminifera records are strongly linearly correlated $\left(r^{2}=0.97\right)$. The data for the larger PETM event, however, deviate strongly from this trend. As described above, it has previously been observed that Eocene hyperthermal pedogenic carbonate CIEs are generally amplified in magnitude relative to their marine counterparts (Bowen et al., 2004; Smith et al., 2007; Schubert and Jahren, 2013). The new data suggest that the mechanisms leading to this amplification were stronger, relative to the size of the event, for the smaller events than for the PETM.

We evaluate this observation in the context of one mechanism, i.e., the sensitivity of land plant photosynthetic ${ }^{13} \mathrm{C}$ discrimination to change in $p \mathrm{CO}_{2}$, which may affect the $\mathrm{C}$ isotope offset between marine and terrestrial substrates differently among events. We conduct two sets of model experiments, adopting a common framework for both based on the assumption that the carbon sources and nature of environmental change during each event were comparable. Although this assumption is likely oversimplistic, it allows us to evaluate the effects of the photosynthetic discrimination mechanism in isolation and to directly evaluate its potential contribution to CIE expression in the new terrestrial records. Specifically, we assume that for each event the CIE magnitude in the atmosphere $\left(\mathrm{D} \delta_{\mathrm{a}, \mathrm{h}}\right)$ is equal to the CIE magnitude in marine (benthic) records. We also assume that peak $p \mathrm{CO}_{2}$ change for each hyperthermal $\left(\mathrm{D} p_{\mathrm{h}}\right)$ is a linear function of marine (benthic) CIE magnitude, which is to some extent supported by the temperature change derived from 


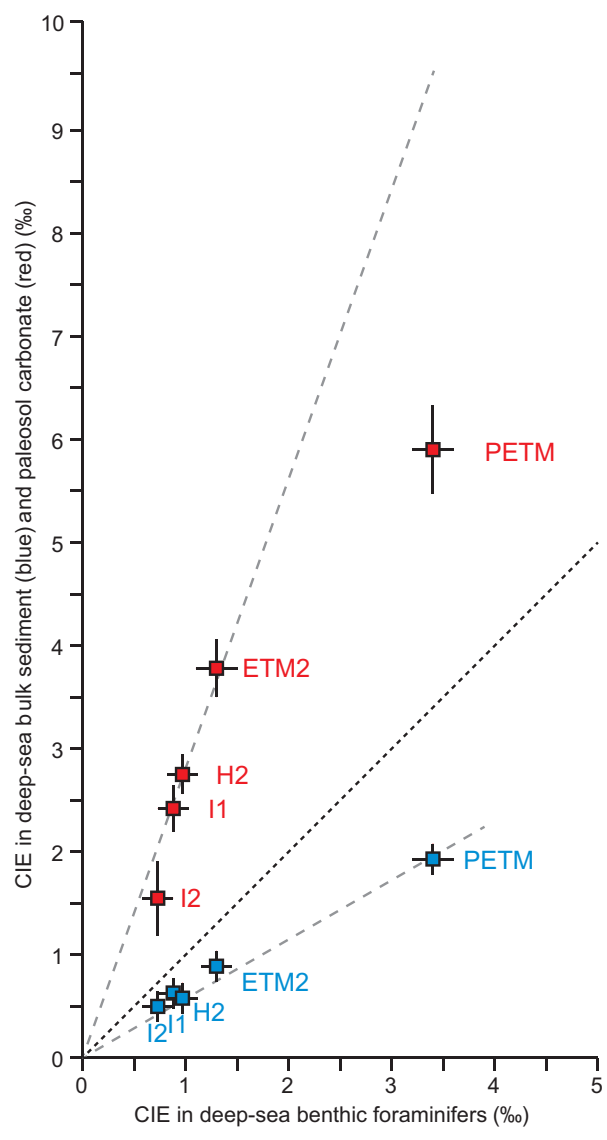

Figure 4. Carbon isotope excursions (CIEs) for the PETM, ETM2, $\mathrm{H} 2$, I1, and $\mathrm{I} 2$ events in the early Eocene compared between different proxies in marine and terrestrial settings. Blue squares denote benthic foraminiferal ( $x$ axis) versus bulk sediment ( $y$ axis) CIEs at Walvis Ridge in the Atlantic Ocean. Red squares denote benthic foraminiferal ( $x$ axis) CIEs at Walvis Ridge versus paleosol carbonate ( $y$ axis) CIEs in the Bighorn Basin, Wyoming (USA). Trend lines are forced through the origin. Note the apparently reduced CIE for the PETM in paleosol carbonate if extrapolation of the trend line through ETM2, H2, I1, and I2 is used.

$\mathrm{D} \delta^{18} \mathrm{O}$ scaling with $\mathrm{D} \delta^{13} \mathrm{C}$ (Stap et al., 2010a; Lauretano et al., 2015), such that

$\mathrm{D} p_{\mathrm{h}}=\mathrm{D} p_{\text {PETM }} \times \mathrm{D} \delta_{\mathrm{a}, \mathrm{h}} / \mathrm{D} \delta_{\mathrm{a}, \mathrm{PETM}}$.

As a starting point for our analysis, we use C-isotope data from leaf wax lipids that constrain the magnitude of the PETM CIE within Bighorn Basin plants $\left(\mathrm{D} \delta_{\mathrm{p}, \mathrm{PETM}} \approx\right.$ $-4.2 \%$; Smith et al., 2007). Decomposing the plant CIE into

$\mathrm{D} \delta_{\mathrm{p}, \mathrm{PETM}}=\mathrm{D} \delta_{\mathrm{a}, \mathrm{PETM}}-\mathrm{D} \Delta_{\mathrm{PETM}}$,

where $\Delta$ is photosynthetic C-isotope discrimination, we solve for the change in discrimination during the PETM ( $+0.8 \%$ o using the Walvis Ridge benthic data to estimate $\mathrm{D} \delta_{\mathrm{a}, \mathrm{PETM}}$.

For any background $p \mathrm{CO}_{2}$ condition prior to the PETM ( $\left.p_{\text {bkg,PETM }}\right)$, we can calculate an estimate of plant carbon isotope discrimination ( $\left.\Delta_{\mathrm{bkg}, \text { PETM }}\right)$ using Eq. (6) of Schubert and Jahren (2012). This idealized value corresponds to fractionation for plants under experimental conditions that are not water or light limiting and is used throughout our modeling when we refer to values of $\Delta$. Adding this value to $D \Delta_{\text {PETM }}$, we obtain an equivalent value for PETM photosynthetic discrimination, $\Delta_{\text {PETM }}$. We then invert the photosynthetic discrimination equation to find the PETM $p \mathrm{CO}_{2}$ concentration $\left(p_{\text {PETM }}\right)$ that gives the estimated discrimination:

$p_{\text {PETM }}=\left(\Delta_{\text {PETM }} \times a / b+\Delta_{\text {PETM }} \times c-a \times c\right) /\left(a-\Delta_{\text {PETM }}\right)$,

where $a=28.26, b=0.21$, and $c=25$ are empirically optimized parameter values (Schubert and Jahren, 2012). Although environmental and physiological factors almost certainly caused the actual, absolute magnitude of plant carbon isotope discrimination in the Paleocene-Eocene Bighorn Basin to be different from the $\Delta$ values calculated here, our results depend only on the change in $\Delta$ between background and hyperthermal conditions and thus on the assumption that the form of the discrimination equation accurately describes the response of Bighorn Basin plants. Below, we discuss how changes in other environmental parameters during hyperthermals may compromise this assumption. We used this approach to calculate values of $p_{\text {PETM }}$ and change in PETM $p \mathrm{CO}_{2}$ (D $p_{\text {PETM }}$ ) across a range of assumed background $p \mathrm{CO}_{2}$ conditions from 250 to $3000 \mathrm{ppmv}$ (figure given in Appendix Fig. B1).

Building on this framework, our first set of model experiments assumes an invariant background $p \mathrm{CO}_{2}$ value across all five events to evaluate whether the nonlinear response of changing photosynthetic discrimination to a range of $\mathrm{D} p_{\mathrm{h}}$ magnitudes across the events can explain the nonlinear CIE scaling observed in the terrestrial records. Using $p_{\text {bkg, } \mathrm{h}}=p_{\text {bkg,PETM }}$ and the $\mathrm{D} p_{\mathrm{h}}$ values estimated for each event, we calculated $D \Delta_{\mathrm{h}}$ for each event using the previously referenced photosynthetic discrimination equation. We then apply Eq. (2) to each event to calculate an estimate of $\mathrm{D} \delta_{p}$ and compare the implied plant CIE magnitude $\left(\mathrm{CIE}_{\mathrm{p}}=0-\mathrm{D} \delta_{\mathrm{p}}\right)$ with the observed soil carbonate CIEs to evaluate whether these scale proportionally across all five events. If change in plant discrimination explains the nonlinear scaling of the paleosol carbonate CIE magnitudes $\left(\mathrm{CIE}_{\mathrm{c}}\right)$, assuming all other soil or environmental influences scale proportionally with event magnitude, then we expect that for all events

$\mathrm{CIE}_{\mathrm{c}, \mathrm{h}}=\mathrm{CIE}_{\mathrm{p}, \mathrm{h}} \times \beta_{1}+\beta_{\mathrm{o}}$.

Nowhere within the range of background $p \mathrm{CO}_{2}$ values tested here is this the case (Fig. 5), suggesting that changing photosynthetic discrimination in isolation and under the assumption of near-constant background $p \mathrm{CO}_{2}$ cannot explain the variation in CIE expression in Bighorn Basin soil carbonates. The exercise shows that large changes in absolute background $p \mathrm{CO}_{2}$ values do not significantly impact the results. 


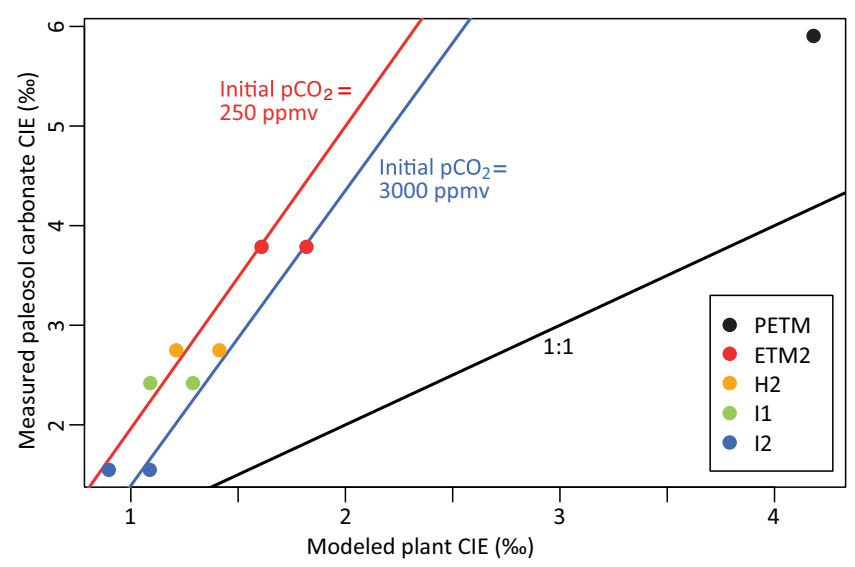

Figure 5. Carbon isotope excursions (CIEs) for the PETM, ETM2, $\mathrm{H} 2$, I1, and $\mathrm{I} 2$ events in the early Eocene compared between paleosol carbonate ( $y$ axis) CIEs in the Bighorn Basin, Wyoming (USA), and measured and modeled plant CIE for two extreme initial $p \mathrm{CO}_{2}$ scenarios. The plant CIE for the PETM is measured (Smith et al., 2007); those of the younger four hyperthermals are modeled (see text for explanation). Note that the trend lines for both extreme $p \mathrm{CO}_{2}$ scenarios do not fit the measured CIEs in plant and pedogenic carbonate for the PETM.

\subsection{Impact on CIE magnitudes of variable background $\mathrm{pCO}_{2}$}

For our second set of experiments, we allow background $p \mathrm{CO}_{2}\left(p_{\mathrm{bkg}}\right)$ to change across the study interval and evaluate the $p_{\text {bkg }}$ conditions required to reconcile the observed pattern of soil carbonate CIE magnitudes with the marine record. Our initial assumptions and estimates of PETM discrimination and $p \mathrm{CO}_{2}$ change are as described in Sect. 3.3.

Here we assume that Eq. (4) does describe the relationship between plant and soil carbonate CIEs and that there are no fixed offset effects (i.e., $\beta_{\mathrm{o}}=0$; all factors that affect the size of the carbonate CIEs relative to the plant CIEs scale linearly with event size). It follows that the plant CIE magnitude for each event is

$$
\mathrm{D} \delta_{\mathrm{p}, \mathrm{h}}=\mathrm{D} \delta_{\mathrm{p}, \mathrm{PETM}} \times \mathrm{D} \delta_{\mathrm{c}, \mathrm{h}} / \mathrm{D} \delta_{\mathrm{c}, \mathrm{PETM}} .
$$

We then calculate the change in photosynthetic discrimination for each event as

$\mathrm{D} \Delta_{\mathrm{h}}=\mathrm{D} \delta_{\mathrm{a}, \mathrm{h}}-\mathrm{D} \delta_{\mathrm{p}, \mathrm{h}}$.

We now have two differences, $\mathrm{D} p_{\mathrm{h}}$ and $D \Delta_{\mathrm{h}}$, for each event. From the photosynthetic discrimination equation, we can write

$\mathrm{D} \Delta_{\mathrm{h}}=\frac{a b\left(p_{\mathrm{bkg}, \mathrm{h}}+\mathrm{D} p_{\mathrm{h}}+c\right)}{a+b\left(p_{\mathrm{bkg}, \mathrm{h}}+\mathrm{D} p_{\mathrm{h}}+c\right)}-\frac{a b\left(p_{\mathrm{bkg}, \mathrm{h}}+c\right)}{a+b\left(p_{\mathrm{bkg}, \mathrm{h}}+c\right)}$.

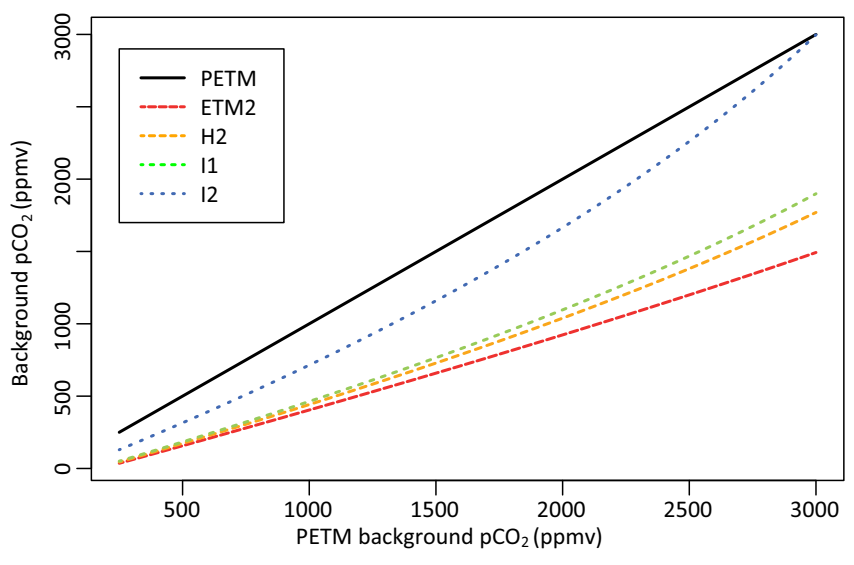

Figure 6. Modeled background $p \mathrm{CO}_{2}$ conditions that result in linear scaling of soil carbonate CIEs relative to the marine record across the five hyperthermals. For each event, change in photosynthetic ${ }^{13} \mathrm{C}$ discrimination is forced by a hyperthermal $p \mathrm{CO}_{2}$ increase, constrained by the model calculations described in the text, over an event-specific background $p \mathrm{CO}_{2}$ condition shown in the figure. The background values shown represent unique solutions where the change in photosynthetic discrimination among events resolves the observed nonlinear scaling of terrestrial relative to marine records. Note that this requires a $>50 \%$ decrease in background $p \mathrm{CO}_{2}$ for most of the post-PETM hyperthermals relative to the PETM.

This can be rearranged to give

$$
\begin{aligned}
& b^{2} p_{\mathrm{bkg}, \mathrm{h}}^{2}+b\left(2 a+2 b c+b \mathrm{D} p_{\mathrm{h}}\right) p_{\mathrm{bkg}, \mathrm{h}}= \\
& a^{2}+2 a b c+a b \mathrm{D} p_{\mathrm{h}}+b^{2} c\left(\mathrm{D} p_{\mathrm{h}}+c\right)-\frac{a^{2} b \mathrm{D} p_{\mathrm{h}}}{\mathrm{D} \Delta_{\mathrm{h}}},
\end{aligned}
$$

a quadratic equation which can be solved to obtain the background $p \mathrm{CO}_{2}$ value required for each hyperthermal to give linear scaling between $\mathrm{CIE}_{\mathrm{p}}$ and $\mathrm{CIE}_{\mathrm{c}}$ across the events (at any prescribed value of $p_{\text {bkg,PETM) }}$.

The analysis suggests that the nonlinear scaling of the soil carbonate CIEs relative to the marine record can be explained across the entire range of assumed $p_{\text {bkg,PETM }}$ conditions through changes in photosynthetic ${ }^{13} \mathrm{C}$ discrimination forced by hyperthermal $p \mathrm{CO}_{2}$ increase over varying background $p \mathrm{CO}_{2}$ conditions (Fig. 6). For any assumed PETM background $p \mathrm{CO}_{2}$, our results require a $>50 \%$ decrease in background $p \mathrm{CO}_{2}$ during the $\sim 2 \mathrm{Myr}$ interval separating the PETM and ETM2. The analysis requires sustained, low background $p \mathrm{CO}_{2}$ which rises gradually across the two subsequent events before a more abrupt increase prior to the I2 event. Across most of the range of initial conditions evaluated, the results require non-hyperthermal background $p \mathrm{CO}_{2}$ values substantially lower than $p_{\text {bkg,PETM }}$ throughout the early Eocene. The fractional change in $p \mathrm{CO}_{2}$ required, relative to PETM background conditions, is lower for higher

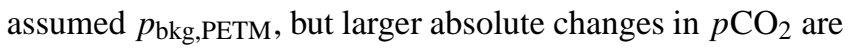
required for these cases. 


\section{Discussion}

\subsection{Fluvial sedimentary archives of the Bighorn Basin}

The presence of five carbon isotope excursions demonstrates that the river floodplain sedimentary successions in the Bighorn Basin firmly record these global atmospheric events. The two new parallel series in the Bighorn Basin confirm the presence of ETM2 and H2 (Abels et al., 2012). The records of the I1 and $\mathrm{I} 2$ events represent the first equivalents in fluvial strata. In the terrestrial realm, a CIE has been found in coal seams in the Fushun Basin, China, which has been related to I1 (Chen et al., 2014), while I2 has not yet been recorded in any other terrestrial record.

The bulk oxide CALMAG proxy data have been proposed to reflect MAP through its influence on soil mineral weathering and cation leaching (Nordt and Driese, 2010; Adams et al., 2011). Here, we conservatively use the method as a proxy for soil moisture rather than mean annual precipitation. The data indicate no or slight increases in soil moisture during the four early Eocene hyperthermals. This strongly deviates from observations of paleohydrologic change for the PETM in the northern and southern Bighorn Basin, where the same proxy indicates a decrease in soil moisture (Kraus and Riggins, 2007; Kraus et al., 2013), consistent with a soil morphology index (Kraus et al., 2013), and analysis of fossil leaves (Wing et al., 2005; Kraus et al., 2013). This would suggest that the regional climatic and/or environmental response to the PETM differed from the post-PETM hyperthermals.

Besides precipitation, temperature, vegetation, and sediment type and rates also have a large impact on soil moisture, and changes in CALMAG geochemical data should be considered in light of changes in these factors (Kraus et al., 2013). For the four younger hyperthermals, there are no temperature or vegetation data available for the Bighorn Basin, while the impact of sediment type and rates needs to be investigated for all five hyperthermals. In this sense, it thus remains uncertain whether the observed opposite CALMAG changes between PETM and the four post-PETM hyperthermals relate to diametrically opposed precipitation trends or environmental (depositional) trends.

The precession forcing of the $7 \mathrm{~m}$ thick overbank-avulsion sedimentary cycles (Abels et al., 2013) is in line with $\sim 100$ and 405 kyr eccentricity forcing of the carbon cycle changes in the ETM2 to I2 stratigraphic interval (Fig. 3). Mudrock intervals with well-developed purple and purple-red paleosols occur predominantly in the eccentricity maxima, while the minima seem to be richer in sand. This could point to a more prolonged relatively stable position of the channel belt on the floodplain, causing less coarse clastic deposition on the floodplains, during eccentricity maxima (Abels et al., 2013). Such an effect could have occurred in combination with or due to more intense pedogenesis under warmer and wetter climates. However, in this interval, the eccentricity-related change is dominated by the hyperthermal events and corroboration of the eccentricity impact is needed from an interval lacking hyperthermals.

\subsection{Marine-terrestrial correlations}

The benthic carbon isotope record of the I1 and I 2 events at Site 1263 reveal very similar patterns as in the bulk and benthic carbon isotope record of Site 1262 (Zachos et al., 2010; Littler et al., 2014) on both eccentricity and precession timescales, as was indicated previously for ETM2 and H2 (Stap et al., 2009). These records even capture very detailed features such as the short-term pre-ETM2 and pre-H2 excursions, and a similar pattern in the $\mathrm{I} 2$ excursion. These patterns were clearly driven by changes in the carbon isotope ratio of the atmosphere-ocean exogenic carbon pool as related to precession forcing (Stap et al., 2009).

Some of these precession-scale details are also captured by the pedogenic carbonate carbon isotope record from the Bighorn Basin suggesting their global nature (Fig. 3). A preETM2 excursion occurs in the McCullough Peaks composite at meter 183, while the shape of the I2 excursion is remarkably similar to the marine records. Main differences on these depth-scale plots are the relative expanded CIE intervals and short recovery phases between $\mathrm{H} 1$ and $\mathrm{H} 2$ and between I1 and I2 in the Bighorn Basin with respect to the Atlantic Ocean records. Sediment accumulation rates were influenced by carbonate dissolution during the events and carbonate overshoot after the events in the marine realm. At the same time, in the Bighorn Basin, sedimentation rates might have been higher during the events due to increased sediment budgets and subsequently lower during their recovery phases. These processes might cause the expanded CIEs and contracted recovery phases in the Bighorn Basin with respect to the marine records when comparing them on a depth scale.

\subsection{Pedogenic carbon isotope excursions}

Deciphering the true scale and timing of ocean-atmosphere $\Delta \delta^{13} \mathrm{C}$ during hyperthermal events is hampered by environmental impacts on carbon isotope fractionation between marine and terrestrial substrates and their proxies (Sluijs and Dickens, 2012). Our comparison of pedogenic carbonate and marine carbon isotope excursions across the five hyperthermal events shows that although each of the CIEs is amplified in magnitude in the soil carbonate records, the PETM soil carbonate CIE magnitude is anomalously small relative to the pattern of amplification seen for the other events. The use of other marine records in this comparison provides similar results. Changes in photosynthetic ${ }^{13} \mathrm{C}$ discrimination alone cannot explain the anomalously small PETM soil carbonate $\mathrm{CIE}$ if we assume that background $p \mathrm{CO}_{2}$ conditions were similar across each of the events (Fig. 5). This mechanism can explain the soil carbonate CIE scaling across the events if there are substantial changes in background $p \mathrm{CO}_{2}$, but the 
required changes involve a $>50 \%$ decline in $p \mathrm{CO}_{2}$ from the end of the Paleocene to the early Eocene. This pattern is not inconsistent with independent $p \mathrm{CO}_{2}$ proxy data from this time interval, but the existing records are too variable and imprecise to provide clear support for or conclusively refute our result (Jagniecki et al., 2015).

Reconciling the pattern of $p \mathrm{CO}_{2}$ change inferred in our analysis with known changes in global climate of the early Eocene is more challenging. The dramatic reduction in $p \mathrm{CO}_{2}$ we estimate following the PETM would be expected to align with a decrease in global temperatures. Although transient cooling has been documented during the $\sim 2 \mathrm{Myr}$ following the PETM (Wing et al., 1999), temperatures had recovered to at least pre-PETM levels by the time of the ETM2, and thereafter continued to warm toward the peak Cenozoic values of the Early Eocene Climate Optimum (Zachos et al., 2008). Benthic oxygen isotope data of Walvis Ridge, Atlantic Ocean, show $\mathrm{a} \sim 1^{\circ} \mathrm{C}$ increase in deep-sea temperature between PETM and ETM2 baseline values (Littler et al., 2014). The substantially lower background $p \mathrm{CO}_{2}$ values required by our analysis for ETM2 and the subsequent hyperthermals would thus imply that non- $\mathrm{CO}_{2}$ greenhouse gases or other mechanisms drove long-term global climatic change during the early Eocene. This is one possible reading of the record of terrestrial CIE amplification across early Eocene hyperthermals and suggests that this record may embed valuable information on long-term changes in atmospheric $p \mathrm{CO}_{2}$, but it is necessary to acknowledge that the interpretations derived here assume that other local, environmental influences on the terrestrial CIE magnitudes were similar in nature and proportional to event size across all of the hyperthermals.

Many other factors may potentially modulate the expression of the global hyperthermal CIEs in the Bighorn Basin pedogenic carbonate records, including changes in temperature effects on carbon isotope fractionation, changes in mixing ratios of atmospheric and organically derived $\mathrm{CO}_{2}$ in soils, and changes in vegetation composition (Bowen et al., 2004; Smith et al., 2007). If each of these factors responded primarily to $\mathrm{CO}_{2}$-driven hyperthermal global change then it is reasonable to assume a proportional, though perhaps nonlinear, magnitude of effect across the suite of events. Our data, however, suggest that at least one potential forcing factor for these effects, soil moisture, changed in a fundamentally different way during the PETM than during the four younger and smaller hyperthermals (Fig. 2). There is a clear indication of soil drying during the PETM-based soil development and chemical proxies in line with plant results (Kraus and Riggins, 2007; Kraus et al., 2013). The data presented here for the subsequent ETM2-I2 events show unchanged or slightly increased soil moisture levels.

Soil moisture, likely reflecting more general changes in local hydroclimate, would be expected to influence the soil carbonate CIE records through changes in the gas-phase permeability of the soil matrix (with wetter soils trapping more organically derived $\mathrm{CO}_{2}$, leading to lower carbonate $\delta^{13} \mathrm{C}$ val- ues), influences on ecosystem productivity (with wetter soils supporting higher productivity, soil respiration, and lower $\delta^{13} \mathrm{C}_{\mathrm{c}}$ ), and changes in plant photosynthetic discrimination (with greater soil water availability increasing discrimination and reducing $\delta^{13} \mathrm{C}_{\mathrm{c}}$; Kohn et al., 2010; Diefendorf et al. 2010). Soil moisture differences between the PETM and younger hyperthermals could also have led to distinct plant community changes affecting the respective CIEs in pedogenic carbonate (Smith et al., 2007).

Evaluating just one of these potential changes, the reconstructed shift in precipitation inferred from PETM proxy data (a reduction in mean annual precipitation from $\sim 1400$ to $\sim 900 \mathrm{~mm}$ year $^{-1}$; Kraus et al., 2013; this study) would, based on data documenting modern relationships between precipitation and photosynthetic discrimination (Kohn et al., 2010; Diefendorf et al., 2010), equate to a reduction in plant discrimination (and thus $\mathrm{CIE}_{\mathrm{c}, \text { PETM }}$ ) of $\sim 0.9$ to $\sim 1.2 \%$. Our data suggest that changes in precipitation were negligible during the younger hyperthermals; thus, this effect could explain $\sim 1 \%$ of the observed $5 \%$ o PETM CIE $\mathrm{C}_{\mathrm{c}}$ anomaly. Clearly this points to the need for a more comprehensive analysis including the effects of discordant local environmental changes on the expression of the global hyperthermal CIEs in soil carbonate records, but it also suggests that in many cases these effect sizes may be modest relative to those arising from $p \mathrm{CO}_{2}$-driven changes in photosynthetic discrimination.

\section{Conclusions}

We recovered carbon isotope excursions of 2.4 and $1.6 \%$, respectively, related to the I1 and I2 events in floodplain sedimentary records from the Bighorn Basin, Wyoming. This adds to the three CIEs found earlier, the PETM, ETM2, and $\mathrm{H} 2$, underlining the sensitivity of these floodplain records for recording global atmospheric changes. Correlations with marine records and eccentricity forcing of hyperthermals corroborate the continuity of sedimentation that occurred in the basin starting above precession timescales of $\sim 20 \mathrm{kyr}$. The $35 \mathrm{~m}$ short eccentricity-driven hyperthermal events are in line with precession forcing of the $7 \mathrm{~m}$ overbank-avulsion sedimentary cycles. Our CALMAG proxy-based soil moisture estimates reproduce similar or slightly enhanced soil moisture contents for the younger four hyperthermals, in contrast to reconstructions for the PETM. More environmental reconstructions, such as from vegetation, are needed for these four younger hyperthermals in the Bighorn Basin to confirm such a remarkable difference. 
We find that the magnitudes of Bighorn Basin soil carbonate CIEs are linearly proportional to those recorded in benthic marine records for the post-PETM hyperthermals but that the soil carbonate CIE for the PETM is $\sim 5 \%$ o smaller than expected based on extrapolation of the relationship observed for the other events. We show that the recently characterized dependence of photosynthetic ${ }^{13} \mathrm{C}$ discrimination on atmospheric $p \mathrm{CO}_{2}$ could explain this PETM excursion magnitude "anomaly" but would require substantially lower background (non-hyperthermal) $p \mathrm{CO}_{2}$ conditions in the early Eocene than at the Paleocene-Eocene boundary. This would require reconciliation with globally increasing temperatures during this time interval. Local environmental effects, such as the proxy-inferred reduction in mean annual precipitation during the PETM, likely also modulated the expression of the global hyperthermal CIEs in the Bighorn Basin soil carbonate records. The record of terrestrial carbonate CIE amplification across the sequence of hyperthermals may embed information on million-year changes in early Eocene $p \mathrm{CO}_{2}$. However, more likely, it records the influence of nonuniform local or regional environmental responses to these events, perhaps reflecting the crossing of a discrete climate system or ecological thresholds during the PETM that were not reached during the smaller, subsequent hyperthermals. 


\section{Appendix A}

Nomenclature

\begin{tabular}{ll}
\hline$a$ & atmosphere \\
bkg & background \\
$\mathrm{CIE}$ & carbon isotope excursion \\
$\mathrm{CIE}_{\mathrm{c}}$ & CIE in paleosol carbonate \\
$D$ & difference \\
$\mathrm{D} \delta$ & carbon isotope excursion magnitude \\
$\Delta$ & photosynthetic C-isotope discrimination \\
$h$ & non-PETM hyperthermal \\
$p$ & pCO 2 \\
$p \mathrm{CO}_{2}$ & atmospheric $\mathrm{CO}_{2}$ pressure \\
$\mathrm{PETM}_{\mathrm{ETM}}$ & Paleocene Eocene Thermal Maximum \\
$P$ & Eocene Thermal Maximum
\end{tabular}

\section{Appendix B}

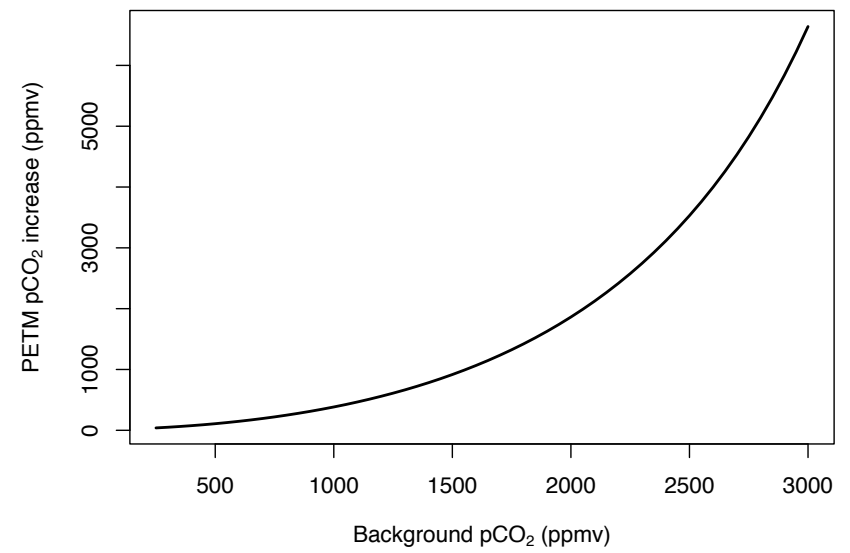

Figure B1. Figure showing $p_{\text {PETM }}$ and change in PETM $p \mathrm{CO}_{2}$ (D $p_{\text {PETM }}$ ) across a range of assumed background $p \mathrm{CO}_{2}$ conditions from 250 to 3000 ppmv. 


\section{Information about the Supplement}

Carbon isotope and soil bulk oxide results for the McCullough Peaks composite section.

\section{The Supplement related to this article is available online at doi:10.5194/cp-12-1151-2016-supplement.}

Acknowledgements. Hemmo A. Abels acknowledges NWOALW for VENI grant 863.11.006. Will Clyde, Jerry Dickens, Frits Hilgen, Jelmer Laks, and Appy Sluijs are thanked for discussions; Arnold van Dijk, David Ecclestone, Jori Jansen, Sophie van Olst, Christine Satter, and Petra Zaal for laboratory assistance; and the Churchill family of Powell, Wyoming, Peter van den Berg, Francien van den Berg, Matthew Gingerich, Marijn Koopman, Jort Koopmans, Sander Smeets, and Karel Steensma for field assistance. We acknowledge the editor, Gerald Dickens, and Brian Schubert and an anonymous reviewer for their constructive input to the manuscript.

Edited by: G. Dickens

\section{References}

Abels, H. A., Clyde, W. C., Gingerich, P. D., Hilgen, F. J., Fricke, H. C., Bowen, G. J., and Lourens, L. J.: Terrestrial carbon isotope excursions and biotic change during Palaeogene hyperthermals, Nature Geosci., 5, 326-329, 2012.

Abels, H. A., Kraus, M. J., and Gingerich, P. D.: Precession-scale cyclicity in the fluvial lower Eocene Willwood Formation of the Bighorn Basin, Wyoming (USA), Sedimentology, 60, 14671483, doi:10.1111/sed.12039, 2013.

Adams, J. S., Kraus, M. J., and Wing, S. L.: Evaluating the use of weathering indices for determining mean annual precipitation in the ancient stratigraphic record, Palaeogeogr. Palaeocl., 309, 358-366, 2011.

Bowen, G. J., Bralower, T. J., Delaney, M. L., Dickens, G. R., Kelly, D. C., Koch, P. L., Kump, L. R., Meng, J., Sloan, L. C., Thomas, E., Wing, S. L., and Zachos, J. C.: Hyperthermal event offers insight into greenhouse warming, Eos, 87, 165-169, 2006.

Bowen, G. J., Beerling, D. J., Koch, P. L., Zachos, J. C., and Quattlebaum, T.: A humid climate state during the Paleocene-Eocene Thermal Maximum, Nature, 432, 495-499, 2004.

Bowen, G. J. and Bowen, B.: Mechanisms of PETM global change constrained by a new record from central Utah, Geology, 36, 379-382, doi:10.1130/G24597A.1, 2008.

Bowen, G. J., Maibauer, B. J., Kraus, M. J., Röhl, U., Westerhold, T., Steimke, A., Gingerich, P. D., Wing, S. L., and Clyde, W. C.: Two massive, rapid releases of carbon during the onset of the Palaeocene-Eocene thermal maximum, Nature Geosci., 8, 44-47, 2015.

Chen, Z., Ding, Z., Tang, Z., Wang, X., and Yang, S.: Early Eocene carbon isotope excursions: evidence from the terrestrial coal seam in the Fushun Basin, Northeast China, Geophys. Res. Lett., 41, 3559-3564, 2014.

Cramer, B. S., Wright, J. D., Kent, D. V., and Aubry, M.-P.: Orbital climate forcing of $\delta^{13} \mathrm{C}$ excursions in the late Paleocene- early Eocene (chrons C24n-C25n), Paleoceanography, 18, 1097, doi:10.1029/2003PA000909, 2003.

Cui, Y., Kump, L. R., Ridgwell, A. J., Charles, A. J., Junium, C. K., Diefendorf, A. F., Freeman, K. H., Urban, N. M., and Harding, I. C.: Slow release of fossil carbon during the Palaeocene-Eocene Thermal Maximum, Nature Geosci., 4, 481-485, 2011.

D'Haenens, S., Bornemann, A., Claeys, P., Röhl, U., Steurbaut, E., and Speijer, R. P.: A transient deep-sea circulation switch during Eocene Thermal Maximum 2, Paleoceanography, 29, 370-388, 2014.

DeConto, R. M., Galeotti, S., Pagani, M., Tracy, D., Schaefer, K., Zhang, T., Pollard, D., and Beerling, D. J.: Past extreme warming events inked to massive carbon release from thawing permafrost, Nature, 484, 87-91, doi:10.1038/nature10929, 2012.

Dickens, G. R.: Methane oxidation during the late Palaeocene thermal maximum, Bull., Soc., Geol., France, 171, 37-49, 2000.

Dickens, G. R., O’Neil, J. R., Rea, D. K., and Owen, R. M.: Dissociation of oceanic methane hydrate as a cause of the carbon isotope excursion at the end of the Paleocene, Paleoceanography, 10, 965-971, 1995.

Dickens, G. R., Castillo, M. M., and Walker, J. C.: A blast of gas in the latest Paleocene: Simulating first-order effects of massive dissocation of oceanic methane hydrate, Geology, 25, 259-262, 1997.

Diefendorf, A. F., Mueller, K. E., Wing, S. L., Koch, P. L., and Freeman, K. H.: Global patterns in leaf ${ }^{13} \mathrm{C}$ discrimination and implications for studies of past and future climate, P. Natl. Acad. Sci., 107, 5738-5743, 2010.

Gingerich, P. D: New earliest Wasatchian mammalian fauna from the Eocene of northwestern Wyoming: composition and diversity in a rarely sampled high-floodplain assemblage, University of Michigan Papers on Paleontology, 28, 1-97, 1989.

Jagniecki, E. A., Lowenstein, T. K., Jenkins, D. M., and Demicco, R. V.: Eocene atmospheric $\mathrm{CO}_{2}$ from the nahcolite proxy, Geology, 43, 1075-1078, 2015.

Kennett, J. P. and Stott, L. D.: Abrupt deep-sea warming, palaeoceanographic changes and benthic extinctions at the end of the Palaeocene, Nature, 353, 225-229, 1991.

Koch, P. L., Zachos, J. C., and Gingerich, P. D.: Correlations between isotope records in marine and continental carbon reservoirs near the Palaeocene/Eocene boundary, Nature, 358, 319322, 1992.

Kohn, M. J.: Carbon isotope compositions of terrestrial C3 plants as indicators of (paleo)ecology and (paleo)climate, P. Natl. Acad. Sci. USA, 107, 19691-19695, doi:10.1073/pnas.1004933107, 2010.

Kraus, M. J. and Riggins, S.: Transient drying during the PaleoceneEocene Thermal Maximum (PETM): Analysis of paleosols in the bighorn basin, Wyoming, Palaeogeogr. Palaeocl., 245, 444-461, 2007.

Kraus, M. J., McInerney, F. A., Wing, S. L., Secord, R., Baczynski, A. A., and Bloch, J. I.: Paleohydrologic response to continental warming during the Paleocene-Eocene Thermal Maximum, Bighorn Basin, Wyoming, Palaeogeogr. Palaeocl., 370, 196-208, 2013.

Lauretano, V., Littler, K., Polling, M., Zachos, J. C., and Lourens, L. J.: Frequency, magnitude and character of hyperthermal events at the onset of the Early Eocene Climatic Optimum, Clim. Past, 11, 1313-1324, doi:10.5194/cp-11-1313-2015, 2015. 
Littler, K., Röhl, U., Westerhold, T., and Zachos, J. C.: A highresolution benthic stable-isotope record for the South Atlantic: Implications for orbital-scale changes in Late Paleocene-Early Eocene climate and carbon cycling, Earth Planet. Sc. Lett., 401, 18-30, 2014.

Lourens, L. J., Sluijs, A., Kroon, D., Zachos, J. C., Thomas, E., Röhl, U., Bowles, J., and Raffi, I.: Astronomical pacing of late Palaeocene to early Eocene global warming events, Nature, 435, 1083-1087, 2005.

McCarren, H., Thomas, E., Hasegawa, T., Röhl, U., and Zachos, J. C.: Depth dependency of the Paleocene-Eocene carbon isotope excursion: Paired benthic and terrestrial biomarker records (Ocean Drilling Program Leg 208, Walvis Ridge), Geochem. Geophy. Geosy., 9, Q10008, doi:10.1029/2008GC002116, 2008.

McInerney, F. A. and Wing, S. L.: The Paleocene-Eocene Thermal Maximum: A pertuarbation of carbon cycle, climate, and biosphere with implications for the future, Annu. Rev. Earth Pl. Sc., 39, 489-516, 2011.

Nicolo, M. J., Dickens, G. R., Hollis, C. J., and Zachos, J. C.: Multiple early Eocene hyperthermals: their sedimentary expression on the New Zealand continental margin and in the deep sea, Geology, 35, 699-702, 2007.

Nordt, L. C. and Driese, S. D.: New weathering index improces paleorainfall estimates from Vertisols, Geology, 38, 407-410, doi:10.1130/G30689.1, 2010.

O'Leary, M. H.: Carbon isotopes in photosynthesis, Bioscience, 38, 328-336, 1988.

Panchuk, K., Ridgwell, A., and Kump, L. R.: Sedimentary response to Paleocene-Eocene Thermal Maximum carbon release: A model-data comparison, Geology, 36, 315-318, doi:10.1130/G24474A.1, 2008.

Ridgwell, A. J.: Marine sedimentary response to massive CO2 release: Implications for interpretation of the PETM, Paleoceanography, 22, PA4102, doi:10.1029/2006PA001372, 2007.

Schubert, B. A. and Jahren, A. H.: The effect of atmospheric $\mathrm{CO}_{2}$ concentration on carbon isotope fractionation in $\mathrm{C}_{3}$ land plants, Geochim. Cosmochim. Acta, 96, 29-43, 2012.

Schubert, B. A. and Jahren, A. H.: Reconciliation of marine and terrestrial carbon isotope excursions based on changing atmospheric $\mathrm{CO}_{2}$ levels, Nature Communications, 4, 1653, doi:10.1038/ncomms2659, 2013.

Sexton, P. F., Norris, R. D., Wilson, P. A., Pälike, H., Westerhold, T., Röhl, U., Bolton, C. T., and Gibbs, S.: Eocene global warming events driven by ventilation of oceanic dissolved organic carbon, Nature, 471, 349-353, 2011.

Sluijs, A. and Dickens, G. R.: Assessing offsets between the $\mathrm{d}^{13} \mathrm{C}$ of sedimentary components and the global exogenic carbon pool across early Paleogene carbon cycle perturbations, Global Biogeochem. Cy., 26, GB4005, doi:10.1029/2011GB004224, 2012.
Smith, F. A., Wing, S. L., and Freeman, K. H.: Magnitude of the carbon isotope excursion at the Paleocene-Eocene thermal maximum: the role of plant community change, Earth Planet. Sc. Lett., 262, 50-65, 2007.

Stap, L., Sluijs, A., Thomas, E., and Lourens, L. J.: Patterns and magnitude of deep sea carbonate dissolution during Eocene Thermal Maximum 2 and $\mathrm{H}_{2}$, Walvis Ridge, southeastern Atlantic Ocean, Paleoceanography, 24, PA1211, doi:10.1029/2008PA001655, 2009.

Stap, L., Lourens, L. J., Thomas, E., Sluijs, A., Bohaty, S., and Zachos, J. C.: High-resolution deep-sea carbon and oxygen isotope records of Eocene Thermal Maximum 2 and $\mathrm{H}_{2}$, Geology, 38, 607-610, 2010a.

Stap, L., Lourens, L., van Dijk, A., Schouten, S., and Thomas, E.: Coherent pattern and timing of the carbon isotope excursion and warming during Eocene Thermal Maximum 2 as recorded in planktic and benthic foraminifera, Geochem. Geophy. Geosy., 11, Q11011, doi:10.1029/2010GC003097, 2010 b.

Thomas, E.: Development of Cenozoic deep-sea benthic foraminiferal faunas in Antarctic waters, in: Origins and Evolution of the Antarctic Biota, edited by: Crame, J. A., Geol. Soc. Sp., 18, 283-296, 1989.

Westerhold, T., Röhl, U., Raffi, I., Fornaciari, E., Monechi, S., Reale, V., Bowles, J., and Evans, H. F.: Astronomical calibration of the Paleocene time, Palaeogeogr. Paleocl., 257, 377-403, 2008.

Wing, S. L., Bao, H., and Koch, P. L.: An early Eocene cool period?, Evidence for continental cooling during the warmest part of the Cenozoic, in: Warm Climates in Earth History, edited by: Huber, B. T., Macleod, K. G., and Wing, S. L., Cambridge University Press, Cambridge, UK, 197-237, 1999.

Zachos, J. C., Röhl, U., Schellenberg, S. A., Sluijs, A., Hodell, D. A., Kelly, D. C., Thomas, E., Nicolo, M., Raffi, I., Lourens, L. J., McCarren, H., and Kroon, D.: Rapid acidification of the ocean during the Paleocene-Eocene Thermal Maximum, Science, 308, 1611-1615, 2005.

Zachos, J. C., Dickens, G. R., and Zeebe, R. E.: An early Cenozoic perspective on greenhouse warming and carbon-cycle dynamics, Nature, 451, 279-283, 2008.

Zachos, J. C., McCarren, H., Murphy, B., Röhl, U., and Westerhold, T.: Tempo and scale of late Paleocene and early Eocene carbon isotope cycles: Implications for the origin of hyperthermals, Earth Planet. Sc. Lett., 299, 242-249, doi:10.1016/j.eps1.2010.09.004, 2010.

Zeebe, R. E., Zachos, J. C., and Dickens, G. R.: Carbon dioxide forcing alone insufficient to explain Palaeocene-Eocene Thermal Maximum warming, Nature Geosci., 2, 576-580, 2009. 